SHS Web of Conferences 24, 01016 (2016)

DOI: $10.1051 /$ shsconf/20162401016

(O) Owned by the authors, published by EDP Sciences, 2016

\title{
Empirical research on the relationship between rural finance development and rural economic growth: A case study of China from 1978 to 2011
}

\author{
Jialin Guo \\ Business School, Central South University of Forestry \& Technology, Changsha, Hunan, China
}

\begin{abstract}
Rural financial development has played a vital role in the process of agricultural economic growth. This article explores the relationship between rural financial development and agricultural economic growth by utilizing China's time series data from 1978 to 2011. The empirical result shows that there is a long-run equilibrium relationship between China's rural financial development and agricultural economic growth and the rural financial development has a negative effect on agricultural economic growth. RFD is the Granger Cause of AEG in 10\% significance level. Based on these empirical results, some rural financial service policies have also been proposed so as to ensure the smooth running of the rural economy.
\end{abstract}

Keywords: rural finance; agricultural growth; co-integration test; granger causality test

\section{INTRODUCTION}

As the core of the modern economy, finance plays an important role in promoting economic growth. On one hand, financial development can give impetus to economic growth directly. On the other hand, financial development can indirectly stimulate economic growth by consumption and investment. As to the research on the relationship between financial development and economic growth, many scholars have their own views. Since the pioneering works of Goldsmith (1969) and Shumpeter (1932), and more recently of McKinnon (1973), Demetriades \& Hussein (1996), César Calderón \& Lin Liu (2003) and Muhsin Kar, et al. (2011), the relationship between financial development and economic growth has been extensively studied. Demetriades \& Hussein (1996) conducted causality tests between financial development and real GDP by using developed time series techniques, and found that there is a causal relationship between financial development and economic growth. César Calderón and Lin Liu (2003) employed the Geweke decomposition test on pooled data to examine the direction of causality between financial development and economic growth, finding that financial development generally leads to economic growth, the Granger causality from financial development to eco- nomic growth and the Granger causality from economic growth to financial development coexist. $\mathrm{Mu}$ hsin Kar, et al. (2011) investigated the direction of causality between financial development and economic growth in the Middle East and North African countries, and the empirical results showed that there is no clear consensus on the direction of causality between financial development and economic growth and, the findings are country specific. All these studies, both theoretical and empirical, have tried to strengthen our understanding of the relationship between financial development and economic growth from different levels.

With the implementation of reform and opening-up, China's economic growth is very significant, especially since the early 1980 s, which is largely due to the reform of its financial system and financial development. Practice development has contributed to the rise of theoretical studies. A great number of theoretical and empirical studies on the relationship between financial development and economic growth in China have emerged. Qi LIANG and Jian-Zhou TENG (2006) explored the relationship between financial development and economic growth based on China's evidence over the period of $1952-2001$. The empirical results suggested that there exists a unidirectional causality from economic growth to financial development. Chen 
(2006) showed that China's financial development contributes to economic growth, and mobilization of savings and the substitution of loans for budget appropriation are the two channels for the financial sector to contribute to the economy. Guariglia and Poncet (2008) examined the relationship between finance and economic growth by using China's data from 1989 to 2003, and found that the indicators measuring state intervention in finance are negatively associated with economic growth, but the indicators measuring market-driven financing are positively associated with economic growth. Jin Zhang et al. (2012) investigated the relationship between financial development and economic growth at city level by using data from 286 Chinese cities over the period of $2001-2006$, and the result from both traditional cross-sectional regressions and first-differenced GMM estimators for dynamic panel data showed that most traditional indicators of financial development are positively associated with economic growth.

Although there are a lot of literature on the relationship between financial development and economic growth at home and abroad, quite a few literatures on the relationship between China's rural financial development and economic growth are also existed. For example, Zhuang Yan (2011) explored the relationship of rural finance and rural economy in Heilongjiang Province, and the empirical analysis suggested that the low level of rural finance in Heilong- jiang province should not have a strong support on the rural economy, but the rural economic development is the Granger causes of rural finance. However, the current literatures on rural financial development and agricultural economic growth are not very systematic, even if there exist a small number of related research literatures. They focus on the role of rural financial development on agricultural economic growth and rarely involve in the agricultural economic impact on rural financial development.

In this paper, we will carry out an empirical study on the relationship between rural financial development and agricultural economic growth based on China's evidence over the period of 1978-2011.

\section{MODEL CONSTRUCTION, METHODOLOGY AND DATA DESCRIPTION}

\subsection{Model construction}

When discussing the implementation way of economic growth, the western mainstream economists establish different models of economic growth based on distinct assumptions.

Endogenous economic growth theory is expanded from the classical "Solow model" and includes many specific models, some of which reveal the transmission mechanism of financial development on economic growth. AK model is a simple but very important endogenous economic growth theory. It is based on the AK model that Pagano (1993) has studied the possible ways of financial development affecting economic growth.

In order to clarify the relationship between rural finance and agricultural economy, we introduce a general form of production function, as shown in the following equation:

$Y(t)=F(K(t), A(t) L(t))$

Wherein, " $t$ " denotes time, " $Y$ " represents the total agricultural output, " $K$ " is the capital element, and " $A L$ " is called the effective labor factor. Learning from growth factor analysis approach proposed by Abramovitz (1956) and Solow (1957), we can decompose the equation (1) and obtain the following equation:

$\dot{Y(t)}=\frac{\partial Y(t)}{\partial K(t)} \dot{K(t)}+\frac{\partial Y(t)}{\partial L(t)} \dot{L(t)}+\frac{\partial Y(t)}{\partial L(t)} \dot{A(t)}$

Divide by $Y$ on both sides of equation (2), and then make appropriate adjustments of the above equation, finally we can easily get equation (3):

$$
\begin{aligned}
& \frac{\dot{Y(t)}}{Y(t)}=\frac{K(t)}{Y(t)} \frac{\partial Y(t)}{\partial K(t)} \frac{\dot{K(t)}}{K(t)}+\frac{L(t)}{Y(t)} \frac{\partial Y(t)}{\partial L(t)} \frac{\dot{L(t)}}{L(t)}+\frac{A(t)}{Y(t)} \frac{\partial Y(t)}{\partial L(t)} \frac{\dot{A(t)}}{A(t)} \\
& =\alpha_{K}(t) \frac{\dot{K(t)}}{K(t)}+\alpha_{L}(t) \frac{\dot{L(t)}}{L(t)}+R(t)
\end{aligned}
$$

In equation (3), $\alpha_{K}(t)$ denotes capital-output elasticity at time $t ; \alpha_{L}(t)$ represents labor-output elasticity of time $t ; R(t)$ is residual value. $R(t)$ is often referred to "Solow residual".

According to the derivation of the above model, we can use the following linear regression model to analyze the impact of rural financial development on agricultural economic growth in China.

$y=\beta_{0}+\sum_{i=1}^{n} \beta_{i} x_{i}+\mu$

What needs to be emphasized is that this article investigates the two-way relationship between rural financial development and rural economic growth.

\subsection{Methodology and data description}

To explore the relationship between rural financial development and rural economic growth in China, we use a Granger-causality test within an ECM model. This test, however, requires that the variables used in a given model be stationary. Many studies have shown that models with non-stationary variables tend to produce spurious regression and make the usual test statistics lack of reliability (Granger \& Newbold, 1974). So we will use the ECM model to analyze the rela- 
tionship between rural financial development and agricultural economic growth in China. The basic steps are as follows:

(1) Unit root test. Unit root tests are mainly used for time series' stationary test. We use the ADF test to examine the stationarity of time series (rural financial development and agricultural economic growth).

(2) Cointegration test. At present, there are two basic methods to test cointegration relationship. One is $\mathrm{ADF}$ test based on the cointegration regression residual. The other is cointegration regression test based on the regression coefficient.

(3) Building ECM model. Davidson et al. (1978) presented the main form of the ECM model. The simple first-order error correction model can be expressed as follows:

$$
\begin{aligned}
& \Delta Y_{t}=\alpha \Delta X_{t}-\lambda e c m_{t-1}+\varepsilon_{t} \\
& e c m_{t-1}=Y_{t}-k X_{t}
\end{aligned}
$$

(4) Granger causality test. If a variable is subject to other variables' lagged effect, we may claim that there exists a Granger causality relationship between them.

To study the relationship between rural financial development and agricultural economic growth, a growth regression model is set up with AEG as the dependent variable. The independent variables include a variable representing rural financial development (RFD) and set controlling for other factors. Dependent variable AEG denotes agricultural economic growth, and $\mathrm{AEG}=$ Agricultural GDP $\div$ GDP. Independent variable RFD represents rural financial development, and $\mathrm{RFD}=$ Agricultural Loans $\div$ Agricultural GDP. All data used in this article are extracted from Comprehensive Statistical Data and Materials on 50 Years of New China, and recent issues of China Statistical Yearbook and China Statistical Yearbook of Agricultural Economics.

\section{EMPIRICAL RESULTS}

\subsection{Unit root test}

Table 1. ADF unit root test results

\begin{tabular}{l|l|l|l|l|l}
\hline \multirow{2}{*}{ Variables } & Test & \multirow{2}{*}{$\begin{array}{l}\text { ADF } \\
\text { test statistics }\end{array}$} & \multicolumn{3}{|l}{ Different significant level } \\
\cline { 4 - 6 } & Type & $1 \%$ & $5 \%$ & $10 \%$ \\
\hline AEG & $(\mathrm{C}, \mathrm{T}, 5)$ & -2.279 & -4.324 & -3.581 & -3.225 \\
\hline$\triangle$ AEG & $(0,0,4)$ & -6.709 & -3.689 & -2.972 & -2.625 \\
\hline RFD & $(\mathrm{C}, \mathrm{T}, 1)$ & -2.433 & -4.273 & -3.558 & -3.212 \\
\hline$\triangle \mathrm{RFD}$ & $(\mathrm{C}, \mathrm{T}, 0)$ & -4.906 & -4.273 & -3.558 & -3.212 \\
\hline
\end{tabular}

Note: $\triangle A E G$ and $\triangle R F D$ respectively denote the first-order difference of original series $A E G, R F G$.

In order to ensure the stationarity of the variables, we adopt standard augmented Dickey-Fuller to make unit root tests on each variable.

The test results (as shown in Table 1) demonstrate that AEG and RFD are non-stationary series. However, $\triangle \mathrm{AEG}$ and $\triangle \mathrm{RFD}$ are staionary series at all different significant levels. This shows that the original data series are one-order integrated series.

\subsection{Cointegration test}

Although some time series themselves are nonstationary, the linear combination of them may be steady. According to the unit root test in table one, AEG and RFD are I(1) time series at different significant level. Therefore, we can continue to use the EG two-step method proposed by Engle and Granger (1987) to make cointegration test through soft EViews 6.0.

The first step is to carry out cointegration regression analysis. And then, we can obtain the following regression equation:

$A E G=0.4516-0.4397 R F D$

$$
(30.75) \quad(-10.9
$$

$R^{2}=0.7880 \quad \bar{R}^{2}=0.781 \quad$ D.W. $=0.55$

The EG cointegration theory tells us, if there exists a cointegration relationship between AEG and RFD, then the residual series must be steady. Therefore, we begin to enter the second step analysis.

The second step is to make stationarity test for residual series. The test results on residual series are shown in Table 2:

Table 2. The ADF unit root test of residual series

\begin{tabular}{l|l|l|l}
\hline \multicolumn{2}{l|l}{ Residual } & T-Statistics & P-Value \\
\hline \multicolumn{2}{l|}{ ADF test statistics } & -3.0289 & 0.0428 \\
\hline \multirow{3}{*}{ Test Critical Value } & $1 \%$ & -3.6537 & \\
\cline { 2 - 3 } & $5 \%$ & -2.9571 & \\
\cline { 2 - 3 } & $10 \%$ & -2.6174 & \\
\hline
\end{tabular}

As is known from Table 2, the residual series of regression equation cointegration are stationary under $5 \%$ significant level. So there is a long-run integration relationship between AEG and RFD. Equation (7) demonstrates that RFD increases per $1 \%$, AEG will reduce $0.4397 \%$ in the long run. Furthermore, an error correction model can be established to analyze the relationship between AEG and RFD.

\subsection{Building ECM model}

Based on the cointegration relationship between AEG and RFD, we can build the following ECM model:

$$
\begin{aligned}
& \triangle A E G_{t}=-0.006037-0.3268 \triangle R F D_{t}-0.1896 E C M_{t-1} \\
& L o g=73.55 \quad A I C=-4.28 \quad S C=-4.14
\end{aligned}
$$


Seen from the value of Log, AIC and SC, we can conclude that equation (8) has passed the significant test, and the short-run fluctuation of AEG is affected by RFD. The error correction coefficient is negative, which meets the requirement of reverse correction mechanism. The result also shows that there is a negative causal relationship between AEG and RFD in China over the period of 1978 - 2011. In the short-term process of dynamic equilibrium, rural financial development (RFD) changes every $1 \%$, agricultural economic growth (AEG) will change $0.3268 \%$ with the opposite direction. The short-term adjustment coefficient is -0.1896 , which means that $0.1896 \%$ of deviation from the AEG to long-term equilibrium value has been adjusted.

\subsection{Granger causality test}

The above results show that there is a long-term stable equilibrium relationship between AEG and RFD. But we cannot make sure whether there exists a causal relationship between them or not. Granger causality test can be used to verify the causal relationship between two variables.

Table 3. Granger causality test

\begin{tabular}{l|l|l|l}
\hline Null Hypothesis & Lags & F-Statistics & P-Value \\
\hline $\begin{array}{l}\text { RFD does not Granger } \\
\text { Cause AEG }\end{array}$ & 2 & 2.7428 & 0.0823 \\
\hline $\begin{array}{l}\text { AEG does not Granger } \\
\text { Cause RFD }\end{array}$ & 2 & 1.5083 & 0.2393 \\
\hline
\end{tabular}

From the test results of Table 3, we can easily find that RFD is a Granger cause of AEG at the $10 \%$ significant level, but AEG is not a Granger cause of RFD at the same significant level. It means that rural financial development (RFD) plays an important supporting role in agricultural economic growth (AEG) in China over the period of 1978-2011, but agricultural economic growth (AEG) is not necessarily an important reason for rural financial development (RFD) at the same period.

\section{CONCLUSIONS AND POLICY IMPLICATIONS}

This paper examines the relationship between rural financial development and agricultural economic growth in China, using time series data over the period of $1978-2011$. We have empirically evaluated the causality between rural financial development and agricultural economic growth, and found that RFD is the Granger cause of AEG while AEG is not the
Granger cause of RFD. Overall, we conclude our findings as follows: (1) Rural financial development has a significant impact on agricultural economic growth in China over the over the period of 1978 2011, but the latter has a very weak influence on the former. (2) There is a long-run integration relationship between AEG and RFD, and a negative causal relationship also exists between them. (3) In the short-term process of dynamic equilibrium, RFD's change will cause AEG's change in the opposite direction. Obviously, our findings have an important implication of policy recommendation. In China, it is critical to establish a well-developed rural financial system, particularly with sound financial intermediation for rural areas. All of them are very important to the efficient allocation of rural credits, which in turn will help the sustainable growth of agricultural economy.

\section{REFERENCES}

[1] Goldsmith, R. 1969. Financial Structure and Development. New York: Yale University Press.

[2] Shumpeter, J. A. 1932. The Theory of Economic Development. Cambridge, MA: Harvard University Press.

[3] McKinnon, R. 1973. Money and Capital in Economic Development. Washington, DC: Brookings Institution.

[4] Panicos O. Demetriades. \& Khaled A. Hussein. 1996. Does financial development cause economic growth? Time-series evidence from 16 countries. Journal of Development Economics, 51: 387-411.

[5] César Calderón \& Lin Liu. 2003. The direction of causality between financial development and economic growth. Joural of Development Economics, 72: 321-334.

[6] Muhsin Kar., Saban Nazlıŏlu \& Hüseyin Ağır. 2011. Financial development and economic growth nexus in the MENA countries: Bootstrap panel granger causality analysis. Economic Modelling, 28: 685-693.

[7] Qi Liang \& Jianzhou Teng. 2006. Financial development and economic growth: Evidence from China. China Economic Review, 17: 395-411.

[8] Chen Hao. 2006. Development of financial intermediation and economic growth: the Chinese experience. China Economic Review, 17: 347-362.

[9] Guariglia, Alessandra \& Poncet, Sandra. 2008. Could financial distortions be no impediment to economic growth after all? Evidence from China. Journal of Comparative Economics, 36: 633-657.

[10] Jin Zhang., Lanfang Wang \& Susheng Wang. 2012. Financial development and economic growth: Recent evidence from China. Journal of Comparative Economics, 40: 393-412.

11] Zhuang Yan. 2011. Empirical Analysis of Rural Finance and Rural Economy in Heilongjiang Province. IEEE Management and Service Science (MASS), Aug. pp. 1-4. 